\title{
Biliary tract intraductal papillary mucinous neoplasm: single-operator cholangioscopy and clearance of mucin obstruction
}
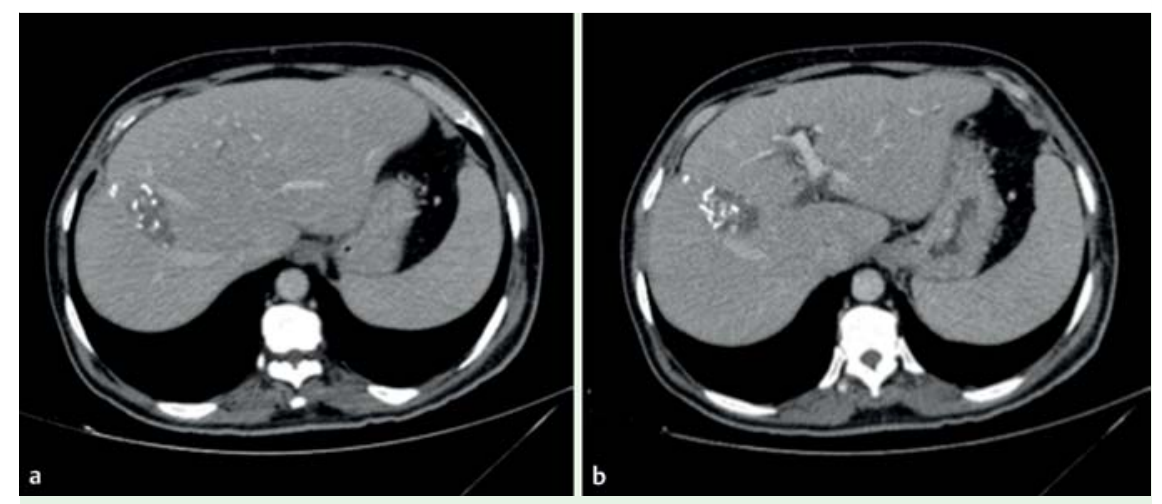

Fig. 1 a, b Biliary duct dilatation seen at abdominal computed tomography (CT), in a 49-year-old man presenting with obstructive jaundice and abdominal pain.
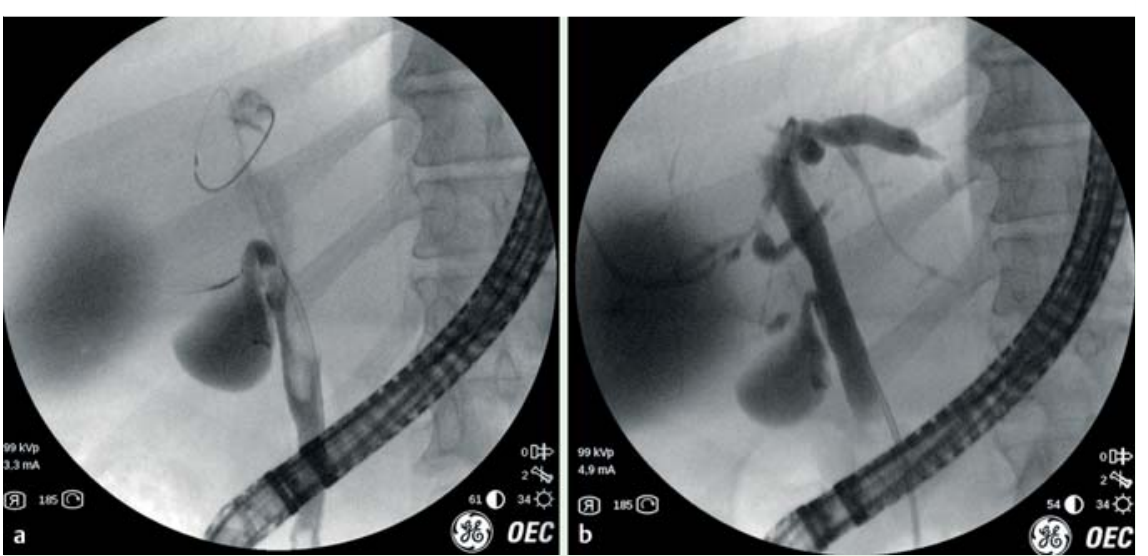

Fig. 2 a, b Endoscopic retrograde cholangiopancreatography (ERCP) showed amorphous filling defects of the common bile duct and occlusion of the right intrahepatic duct.

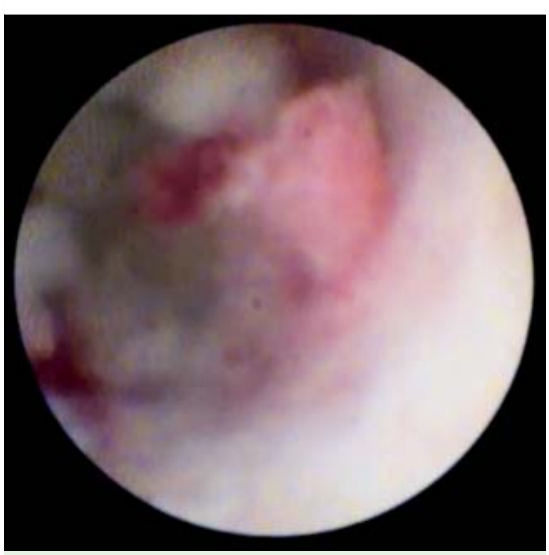

Fig. 3 Biliary lesion seen at single-operator cholangioscopy.

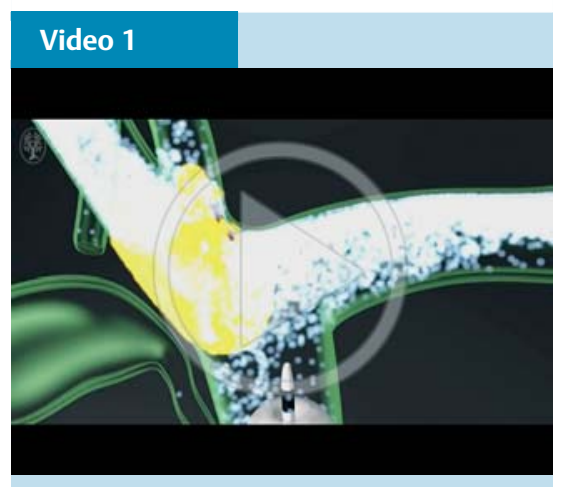

Biliary tract intraductal papillary mucinous neoplasm: clearance of mucin clot and SpyGlass cholangioscopy-guided biopsies.
Biliary tract intraductal papillary mucinous neoplasm (BT-IPMNs) are the counterparts of pancreatic IPMNs, and are characterized as papillary lesions that produce mucin and spread along the biliary mucosa causing obstructive jaundice [1]. These tumors can develop anywhere along the biliary tree, and are considered to be premalignant lesions [2]. We report a case of a BT-IPMN diagnosed by cholangioscopy-guided biopsy, and a novel technique of clearing the biliary tree with a mucolytic solution.

A 49-year-old man presented with obstructive jaundice (serum bilirubin $15 \mathrm{mg} / \mathrm{dL}$ ) and abdominal pain. Contrast computed tomography showed focal dilatation of bile ducts in segments IV and VIII and dilatation of the common bile duct, with no stones or adenopathy ( $\bullet$ Fig. 1 a, - Fig.1b). Endoscopic retrograde cholangiopancreatography (ERCP) detected amorphous filling defects of the common bile duct with poor opacification of the intrahepatic ducts, especially at the right side ( Fig. 2 a, $\bullet$ Fig. 2 b). As a mucin clot was obstructing bile flow, a 5-minute wash with mucolytic agent (n-acetyl cysteine) through an inflated extractor balloon ( Video 1 ) was done to improve clearance. Single-operator cholangioscopy (SpyGlass; Boston Scientific, Natick, Massachusetts, USA) was performed to evaluate the extent and involvement of the tumor growth within the bile duct as well as to provide direct-view biopsies ( $\mathrm{Fig} .3$ ). A protruded, friable 8 -mm lesion, located in the right intrahepatic duct, was biopsied and histopathological examination revealed a mucinous papillary neoplasm without dysplasia ( $\bullet$ Fig.4a, $\bullet$ Fig.4b). The patient recovered without adverse events, his serum bilirubin levels decreased to $2 \mathrm{mg} / \mathrm{dL}$, and a surgical resection was planned.

BT-IPMN is a rare variant of bile duct tumor, with malignancy varying on several reports to as high as $64 \%-89 \%[1,3,4]$. Clinical presentations include abdominal pain, jaundice, and acute cholangitis. Peroral cholangioscopy can assess the spread of the tumor and allows histological confirmation, providing better information for surgical planning [5]. We undertook a novel approach of mucin removal by injection of a mucolytic agent, thus improving biliary clearance before surgery.

Endoscopy_UCTN_Code_TTT_1AR_2AD 

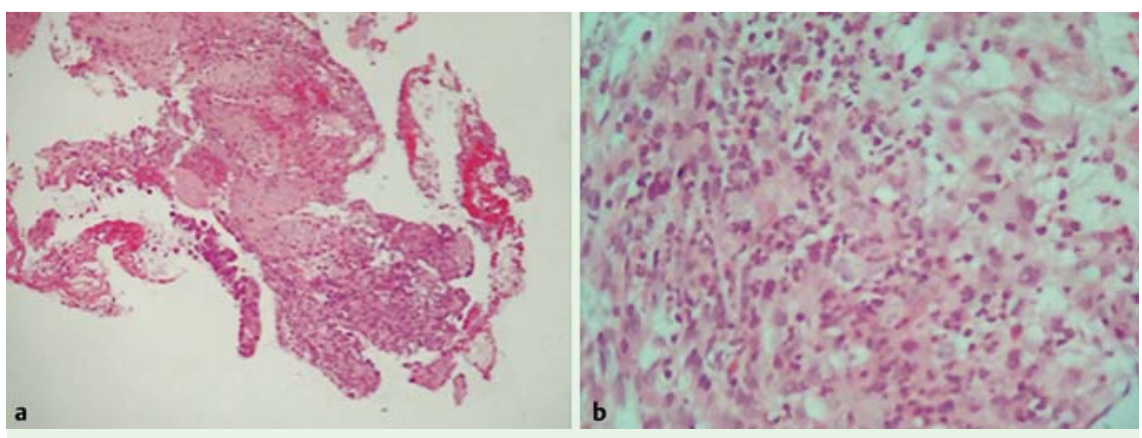

Fig.4 a, b Histopathological appearances of a mucinous papillary neoplasm.

\section{Tomazo Franzini ${ }^{1}$, Renata Nobre Moura', Silvia L. Alves de Lima', Gustavo Rodela ${ }^{1}$, Frederico Ribeiro Teixeira Jr², Humberto Kishi ${ }^{3}$, Eduardo Guimarães Hourneax de Moura ${ }^{1}$}

${ }^{1}$ Endoscopy Unit, Department of Gastroenterology, University of Sao Paulo Medical School, Brazil

${ }^{2}$ Department of General Surgery, University of Sao Paulo Medical School, Brazil ${ }^{3}$ Department of Pathology, University of Sao Paulo Medical School, Brazil
4 Rocha FG, Lee H, Katabi $N$ et al. Intraductal papillary neoplasm of the bile duct: a biliary equivalent to intraductal papillary mucinous neoplasm of the pancreas? Hepatology 2012; 56: $1352-1360$

5 Moura EG, Franzini T, Moura RN et al. Cholangioscopy in bile duct disease: a case series. Arq Gastroenterol 2014; 51: 250-254

Bibliography

DOI http://dx.doi.org/

10.1055/s-0042-105564

Endoscopy 2016; 48: E150-E151

(c) Georg Thieme Verlag KG

Stuttgart · New York

ISSN 0013-726X

\section{References}

1 Ohtsuka M, Shimizu H, Kato A et al. Intraductal papillary neoplasms of the bile duct. Int J Hepatol 2014. Article ID 459091. DOI: 10.1155/2014/459091

2 Barton JG, Barrett DA, Maricevich MA et al. Intraductal papillary mucinous neoplasm of the biliary tract: a real disease? HPB (Oxford) 2009; 11: 684-691

3 Wang $X$, Cai $Y Q$ Chen $Y H$ et al. Biliary tract intraductal papillary mucinous neoplasm: report of 19 cases. World J Gastroenterol 2015; 21 : $4261-4267$

\section{Corresponding author}

\section{Tomazo Franzini, MD}

Av. Dr. Enéas de Carvalho Aguiar 255

Prédio dos Ambulatórios

Pinheiros

Sao Paulo 05403-000, SP

Brasil

Fax: +55-11-26616460

tomazof@uol.com.br 